\title{
A retrospective study of pattern of recurrence after radical surgery for thoracic esophageal carcinoma with or without postoperative radiotherapy
}

\author{
YICHUN WANG ${ }^{1}$, LI ZHANG ${ }^{1}$, DONGMEI YE ${ }^{2}$, WANLI XIA ${ }^{2}$, JUN JIANG ${ }^{1}$, \\ XIUMEI WANG ${ }^{1}$, MINGXIA ZHANG $^{1}$ and FAN WANG $^{1}$ \\ Departments of ${ }^{1}$ Radiation Oncology and ${ }^{2}$ Thoracic Surgery, First Affiliated Hospital of Anhui Medical University, \\ Hefei, Anhui 230022, P.R. China
}

Received August 24, 2017; Accepted January 11, 2018

DOI: $10.3892 / \mathrm{ol} .2018 .7807$

\begin{abstract}
The present study aimed to investigate the recurrence pattern of thoracic esophageal cancer (TEC) following radical surgery for guiding postoperative radiotherapy (PRT). Patterns of recurrence were analyzed in patients with recurrence for the first time after radical surgery at the First Affiliated Hospital of Anhui Medical University (Anhui, China) from January 2012 to December 2015. A total of 244 patients were reviewed in the study. The mean recurrence time for patients with PRT was $>1$ month longer than that for patients without PRT. The lymphatic, anastomotic and hematological recurrence ratios were 87.9 vs. $69.2 \%, 4.0$ vs. $11.5 \%$ and 8.0 vs. $17.2 \%$, respectively for patients without and with PRT. The most common recurrence regions were staion1 and station $2-4$ (30.0 vs. $36.5 \%$ and $37.2 \%$ vs. $23.1 \%$, respectively, for patients without and with PRT). The lymphatic recurrence of upper TEC was almost in station1 and station 2-4 (infield). The middle and lower TEC also had a high probability of lymphatic recurrence in station 1 and station 2-4 (totally 76.3 vs. $57.6 \%$ and 61.9 vs. $61.1 \%$, respectively). The recurrence ratio significantly decreased in station 2-4 (infield) for middle TEC patients with PRT compared with patients without PRT $(\mathrm{P}=0.03)$, while no significant differences in the lymphatic recurrence ratios were observed in other regions $(\mathrm{P}>0.05)$. The differences of recurrence ratios in station 7 , station 8 and celiac regions (infield) for lower TEC patients without and with PRT also demonstrated no statistical significance ( $P>0.05)$. The results of the present study indicated that the lower neck, supraclavicular regions and upper mediastinal
\end{abstract}

Correspondence to: Dr Yichun Wang or Dr Fan Wang, Department of Radiation Oncology, First Affiliated Hospital of Anhui Medical University, 218 Jixi Road, Hefei, Anhui 230022, P.R. China

E-mail: wangechun321@sina.com

E-mail: wangfan1965@sina.com

Key words: recurrence, esophageal cancer, esophagectomy, radiotherapy, clinical target volume regions (station 1,2 and 4) should be included in the clinic target volume (CTV) for PRT, while lower mediastinal regions, celiac regions and anastomotic may not be included in CTV.

\section{Introduction}

Esophageal carcinoma (EC) is a common upper gastrointestinal tumor, with the third incidence and the fourth mortality in China (1). Despite improvements in diagnosis and treatments of esophageal cancer patients, overall 5-year survival rates were still very low $(-40 \%)(1,2)$. Esophagectomy is the standard strategy for resectable EC. Unfortunately locoregional recurrence [especially lymphatic metastasis (LNM)] was the main failure for these patients $(3,4)$.

Multimodality treatment has become increasingly used for EC, which proved to have good outcomes (5). Neoadjuvant chemoradiotherapy was proved to be a better strategy for local advanced patients $(6,7)$. Postoperative radiotherapy (PRT) was only recommended for positive margin patients in NCCN guidelines (8). However, in most area of China, surgery was still the first choice of EC patients by now. Postoperative chemoradiotherapy was controversial and had been studied for many years. Several Meta analyses concluded that postoperative chemoradiotherapy significantly decreased postoperative mortality, local recurrence and distant metastasis rates, with no increased postoperative complications for patients with resectable esophageal carcinoma (9-11).

The lymphatic drainage of esophagus is great complexity, which not only runs through transversely to the adjacent lymph nodes, but also vertically to distant nodes $(12,13)$. Early EC with the submucosa infiltrated, therefore, can be found widely metastasis, even skipping metastasis $(14,15)$. Because of the complexity lymphatic drainage of esophageal carcinoma, it is difficult to determine the target of postoperative volume. After surgery, the anatomy of esophagus and lymphatic drainage changed. Therefore, the postoperative target volume is different from that of non-operative radiotherapy. Many target plans have been used in past decades $(16,17-21)$, without a standard criterion.

In order to find out the failure pattern after surgery, several retrospective studies had been investigated and advices were 
concluded for clinic target delineation (22-25). However, these researches were focused on the patients without PRT. Few papers were found to investigate the pattern of recurrence after PRT using a specific target. In this study, recurrence pattern after radical surgery was investigated by retrospective analysis of TEC patients with and without PRT aimed to find an appropriate plan for PRT.

\section{Patients and methods}

Patients. The present study was a retrospective investigation to assess recurrence rates in patients that have undergone a radical esophagectomy for thoracic EC, with or without PRT. From January 2012 to December 2015, patients with recurrence who underwent radical esophagectomy for thoracic esophageal carcinoma were collected at the First Affiliated Hospital of Anhui Medical University. Tumor locations were based on the Japanese classification system (26). Clinic pathological characteristics (tumor invasion, node, metastasis and stage) were based on the tumor-node-metastasis (TNM) classification (7th edition), by the International Union against Cancer (27). Lymphatic station was classified based on American Thoracic Society/International Association for the Study of Lung Cancer (IASLC) lymph node station nomenclature (28).

Case selection. Inclusion criteria: Thoracic CT, abdominal B-ultrasound, and other images were made to exclude distant metastasis in all patients before surgery; All patients were proved to be TEC by pathologic examination after surgery; All patients were proved to have postoperative recurrence for the first time by the following ways: clinical, cytology or pathology, and B-ultrasound, CT or MRI, and other imaging ways (i.e., PET/CT). Exclusion criteria: Patients with unknown or unclear pathological characterization; patients without sufficient evidence to support clinic or pathological recurrence; patients with unknown lymph node station; patients associated with other tumor; patients with unknown target or target not accordance with the principle which discussed below for PRT.

The diagnosis of recurrence. The diagnosis of neck/supraclavicular LNM was mainly based on physical examination, B-ultrasound, CT/MRI and fine needle aspiration. The diagnosis of mediastinal LNM was mainly based on CT, MRI, or PET/CT. The diagnosis of celiac LNM was mainly based on B-ultrasound, CT or PET/CT. The short diameter $>10 \mathrm{~mm}$ ( $5 \mathrm{~mm}$ for lymph nodes of tracheoesophageal groove) or fusion of lymph nodes or whatever size of lymph node combined with hoarseness or cough was considered as mediastinal LNM in CT/MRI image, while HUVmax value of lymph nodes $>4.0$ in PET/CT (29). The diagnosis of anastomotic recurrence was based on esophagoscopy. The diagnosis of hematological recurrence was based on mageological diagnosis according to different positions.

PRT. Patients with pT3-4 or $\mathrm{pN}(+)$ were carried out PRT in Radiation Oncology Department of my hospital. The time interval was 3-12 months. The most common scheme was $50 \mathrm{~Gy} / 25$ fractions, 2 Gy/day, and 5-6 fractions/week. Dose of two patients was $<50 \mathrm{~Gy}$ and dose of five patients was $>50 \mathrm{~Gy}$, 2 Gy/fraction. Conformal computed tomography-based planning and a linear accelerator were used to delivery external beam radiation therapy for these patients. The clinical target volume (CTV) included tumor bed and lymphatic drainage regions at high risk. The principle of CTV was as follows: Upper TEC: The tumor bed with a $3 \mathrm{~cm}$ enlargement superiorly and inferiorly, station 1 , station 2, station 4, station 5 and station 7; Middle TEC: The tumor bed with a $3 \mathrm{~cm}$ enlargement superiorly and inferiorly, station 2 , station 4 , station 5 and station 7; Lower TEC: The tumor bed with a $3 \mathrm{~cm}$ enlargement superiorly and inferiorly, station 7 , station 8 , and cardia and left gastric lymph nodes. The planning target volume (PTV) was defined as the CTV plus a $0.5-0.8 \mathrm{~cm}$ margin.

Follow-up. In the first 2 years, patients were followed-up every 3 months after surgery and every 6 months thereafter. Re-examinations included chest enhanced CT scans, abdominal and cervical ultrasound screening. When necessary, cervical or abdominal CT, PET/CT, endoscopy, and fine needle aspiration according to specific symptoms.

Statistical analysis. Statistical analysis was performed using the statistical package SPSS (version 19.0 for Windows, IBM SPSS, Armonk, NY, USA). Chi-square and Fisher's test were used in qualitative variables. Student's t-test was used for continuous variables. $\mathrm{P}<0.05$ was considered to indicate a statistically significant difference.

\section{Results}

Characterization of patients. A total of 244 patients were collected for the present study, clinical and pathological characteristics were shown in Table I. Proportion of pT3-4 and $\mathrm{pN}(+)$ patients with PRT was more than that of patients without PRT $(\mathrm{P}=0.04 ;<0.01$, respectively). Among 196 patients treated without PRT, the mean recurrence time (MT) was $14.22 \pm 0.88$ months (1.0-61.0 months) after operation, while MT was 15.37 \pm 1.53 months (3.0-54.0 months) for the other 48 patients who treated with PRT. The recurrence time of these two groups had no significant difference. The recurrence time was shown in Fig. 1.

The common symptoms for those patients were mass found in the lower neck and supraclavicular regions (27.5\%), hoarse voice $(27.9 \%)$, and local pain $(14.2 \%)$, while a large number $(27.5 \%)$ were found with no symptom by using imaging examinations (i.e., chest CT/MRI, abdominal B-ultrasound, $\mathrm{PET} / \mathrm{CT})$. The symptoms for these patients were shown in Fig. 2.

\section{Pattern of recurrence after radical surgery}

Distribution. Among the 249 patients, a total of 332 sites (274 for patients without PRT, 52 for patients with PRT) of recurrence were found and the distribution of sites was shown in Table II. The patterns of initial recurrence included lymphatic recurrence, anastomotic recurrence and hematological recurrence for patients without and with PRT, as shown in Fig. 3A. The lymphatic recurrence ratio was $87.9 \%$ (241/274) vs. $69.2 \%$ $(36 / 52)$, the difference had statistical significance $(\mathrm{P}=0.01)$. The anastomotic recurrence ratio was $4.0 \%(11 / 274)$ vs. $11.5 \%$ $(6 / 52)$, the difference had statistical significance $(\mathrm{P}=0.03)$. The 
Table I. Clinical and pathological characteristics of patients $(n=244)$.

\begin{tabular}{|c|c|c|c|}
\hline Parameters & $\begin{array}{l}\text { Without PRT } \\
\quad(n=196)\end{array}$ & $\begin{array}{l}\text { With PRT } \\
(\mathrm{n}=48)\end{array}$ & P-value \\
\hline Age (years) & & & 0.94 \\
\hline$\leq 60$ & 87 & 21 & \\
\hline$>60$ & 109 & 27 & \\
\hline Sex & & & 0.57 \\
\hline Male & 165 & 42 & \\
\hline Female & 31 & 6 & \\
\hline T stage & & & 0.04 \\
\hline pT1-2 & 81 & 12 & \\
\hline pT3-4 & 115 & 36 & \\
\hline $\mathrm{N}$ stage & & & 0.01 \\
\hline $\mathrm{pN}(-)$ & 108 & 11 & \\
\hline $\mathrm{pN}(+)$ & 88 & 37 & \\
\hline Differentiation & & & 0.04 \\
\hline Poor & 53 & 22 & \\
\hline Moderate & 96 & 19 & \\
\hline Well & 47 & 7 & \\
\hline Tumor location & & & 0.11 \\
\hline Upper & 20 & 1 & \\
\hline Middle & 114 & 29 & \\
\hline Lower & 62 & 18 & \\
\hline Type of tumor & & & 0.76 \\
\hline $\mathrm{SCC}$ & 183 & 46 & \\
\hline Others & 13 & 2 & \\
\hline Chemotherapy & & & - \\
\hline $0-2$ cycles & - & 31 & \\
\hline$\geq 3$ cycles & - & 17 & \\
\hline Lymphadenectomy & & & 0.36 \\
\hline Two-field & 147 & 39 & \\
\hline Three-field & 49 & 9 & \\
\hline Anastomotic site & & & 0.60 \\
\hline Neck & 29 & 9 & \\
\hline Upon aortic arch & 137 & 34 & \\
\hline Below aortic arch & 30 & 5 & \\
\hline
\end{tabular}

SCC, squamous cell carcinoma; PRT, postoperative radiotherapy.

hematological recurrence ratio was $8.0 \%$ (22/274) vs. $17.2 \%$ (10/52), the difference had statistical significance $(\mathrm{P}=0.01)$.

Fig. 3B shows the lymphatic recurrence ratio in different regions. The recurrence ratios of station 1 , station 2-4, station 5, station 7, station 8, station 10 and celiac regions were $30.0 \%(96 / 274)$ vs. $36.5 \%(19 / 52), 37.2 \%(102 / 274)$ vs. $23.1 \%$ $(12 / 52), 1.1 \%(3 / 274)$ vs. $0.0 \%(0 / 52), 2.6 \%(7 / 274)$ vs. $1.9 \%$ $(1 / 52), 2.6 \%(7 / 274)$ vs. $0.0 \%(0 / 52), 1.8 \%(5 / 274)$ vs. $0.0 \%$ (0/52), $7.7 \%(21 / 274)$ vs. $5.8 \%(3 / 52)$, respectively for patients without and with PRT. The difference of recurrence ratio in each region for patients without and with PRT had no statistical significance $(\mathrm{P}>0.05)$.
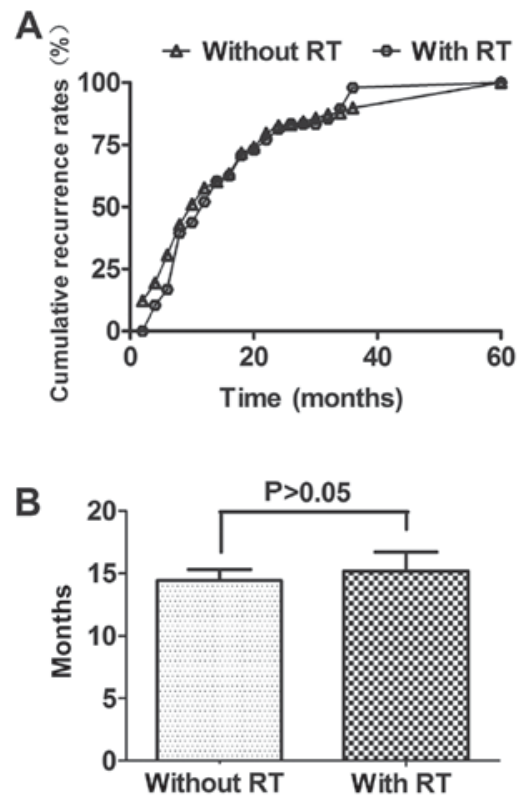

Figure 1. Time to recurrence for patients following esophagectomy (A) Cumulative recurrence rate at different recurrence times. (B) Mean recurrence time. RT, radiotherapy.

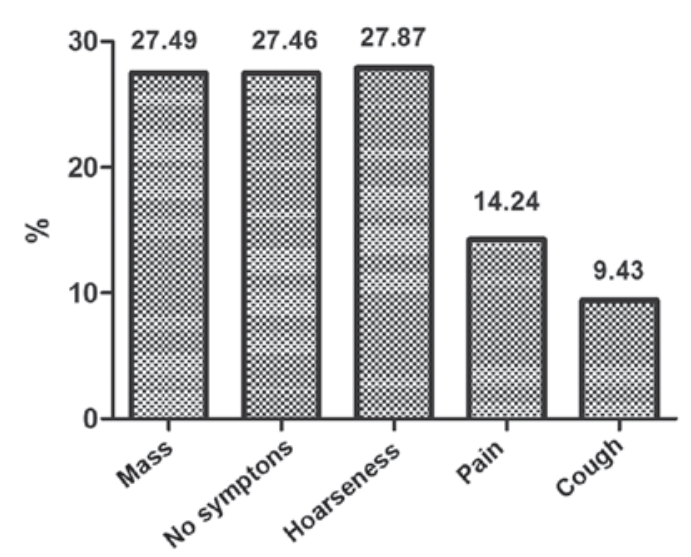

Figure 2. Symptoms of recurrence for all patients.

Fig. 3C-E shows the lymphatic recurrence ratios in different regions of patients without and with PRT in different locations. For upper TEC, the differences of recurrence ratio in each region for patients without and with PRT had no statistical significance $(\mathrm{P}>0.05)$. For middle TEC, the difference of recurrence ratio in station 2-4 for patients without and with PRT had statistical significance $(\mathrm{P}=0.03)$, while other regions had no statistical significance $(\mathrm{P}>0.05)$. For lower TEC, the differences of recurrence ratio in each region for patients without and with PRT had also no statistical significance $(\mathrm{P}>0.05)$.

Relation between recurrence and target for radiotherapy patients. We defined the recurrence in the primary target as infield recurrence, while the others as outfield recurrence. Among 53 patients with PRT, recurrence ratio of infield was $25.0 \%(13 / 52)$. Univariate analysis showed that the location of tumor was the influence factor for infield recurrence. The upper TEC had a higher infield recurrence $(100.0 \%)$, while the middle and lower TEC had a higher outfield recurrence 
Table II. Location of recurrence patterns in patients.

\begin{tabular}{|c|c|c|c|c|c|c|c|c|}
\hline \multirow[b]{2}{*}{ Location } & \multicolumn{2}{|c|}{ Upper } & \multicolumn{2}{|c|}{ Middle } & \multicolumn{2}{|c|}{ Lower } & \multicolumn{2}{|c|}{ Total } \\
\hline & $\begin{array}{c}\text { Without } \\
\text { PRT }\end{array}$ & $\begin{array}{l}\text { With } \\
\text { PRT }\end{array}$ & $\begin{array}{c}\text { Without } \\
\text { PRT }\end{array}$ & $\begin{array}{l}\text { With } \\
\text { PRT }\end{array}$ & $\begin{array}{c}\text { Without } \\
\text { PRT }\end{array}$ & $\begin{array}{l}\text { With } \\
\text { PRT }\end{array}$ & $\begin{array}{c}\text { Without } \\
\text { PRT }\end{array}$ & $\begin{array}{l}\text { With } \\
\text { PRT }\end{array}$ \\
\hline \multicolumn{9}{|l|}{ Supraclavicular } \\
\hline Station 1 & 12 & 0 & 55 & 12 & 29 & 7 & 96 & 19 \\
\hline \multicolumn{9}{|l|}{ Mediastinal } \\
\hline Station 2-4 & 12 & 1 & 67 & 7 & 23 & 4 & 102 & 12 \\
\hline Station 5 & 0 & 0 & 3 & 0 & 0 & 0 & 3 & 0 \\
\hline Station 7 & 0 & 0 & 4 & 0 & 3 & 1 & 7 & 1 \\
\hline Station 8 & 0 & 0 & 4 & 0 & 3 & 0 & 7 & 0 \\
\hline Station 10 & 0 & 0 & 2 & 0 & 3 & 0 & 5 & 0 \\
\hline Celiac & 1 & 0 & 8 & 2 & 12 & 1 & 21 & 3 \\
\hline Anastomotic & 2 & 0 & 5 & 4 & 4 & 2 & 11 & 6 \\
\hline Hematological & 3 & 0 & 12 & 8 & 7 & 3 & 22 & 11 \\
\hline Total & 30 & 1 & 160 & 33 & 84 & 18 & 274 & 52 \\
\hline
\end{tabular}

There was no lymphatic recurrence in station 3, station 6 and station 9. PRT, postoperative radiotherapy.

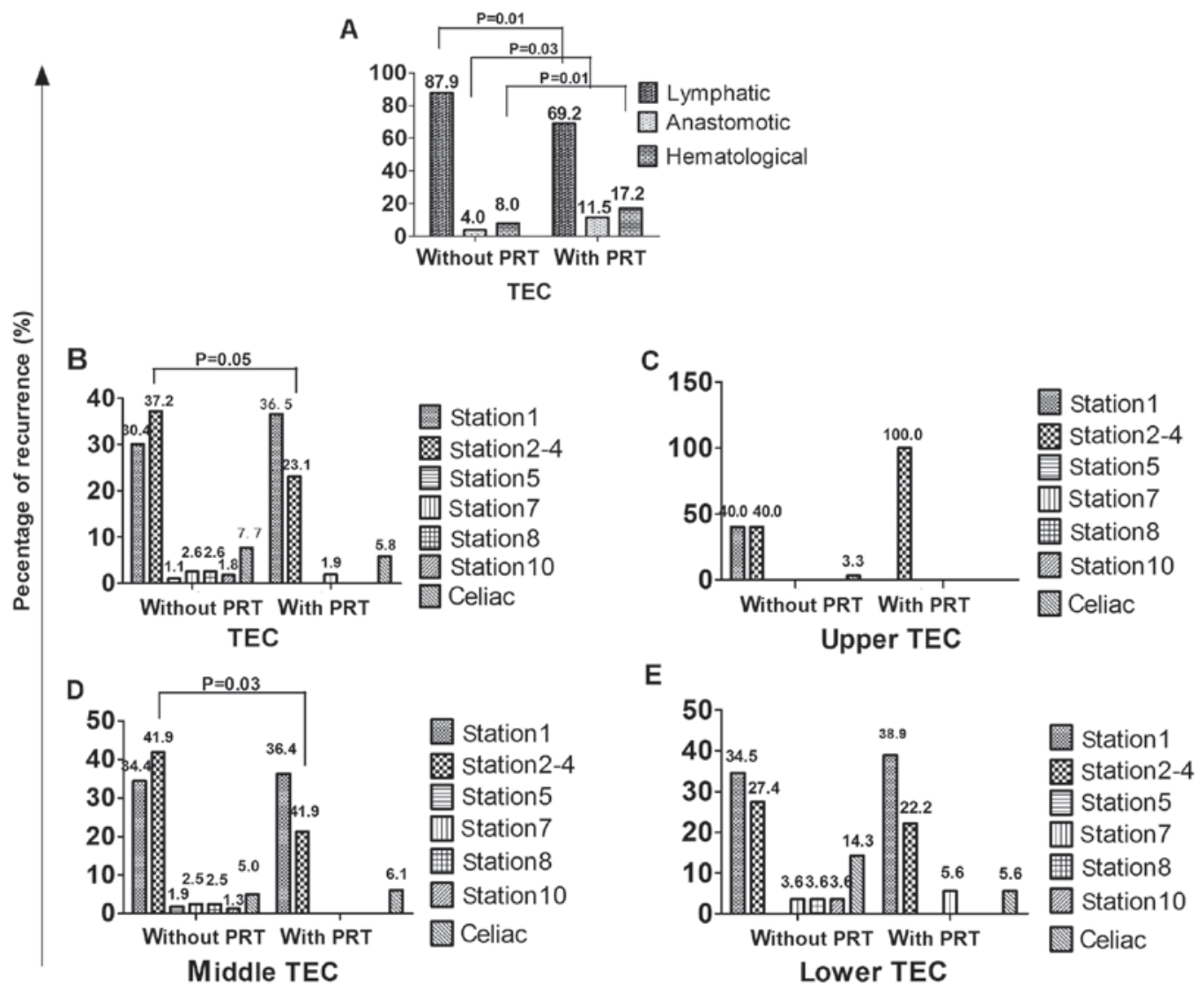

Figure 3. Ratios of recurrence for patients with and without PRT (the difference of recurrence rate in each region unlabeled was P $>0.05$ ). (A) Ratios of lymphatic recurrence, anastomotic and distant hematological site. (B) Ratios of recurrence in different regions. (C) Ratios of recurrence in different regions for upper TEC. (D) Ratios of recurrence in different regions for middle TEC. (E) Ratios of recurrence in different regions for lower TEC. PRT, postoperative radiotherapy; TEC, thoracic esophageal cancer.

(67.7, $88.9 \%$, respectively). The differences in different locations had a statistical significance $(\mathrm{P}=0.02)$. The pattern of infield and outfield recurrences was shown in Table III.

\section{Discussion}

In the present study, we found that there was no statistical 
Table III. Univariate analysis for infield and outfield recurrence for patients with PRT.

\begin{tabular}{|c|c|c|c|}
\hline Parameters & $\begin{array}{l}\text { Infield } \\
(n=13)\end{array}$ & $\begin{array}{l}\text { Outfield } \\
(n=39)\end{array}$ & P-value \\
\hline Age (years) & & & 0.18 \\
\hline$\leq 60$ & 10 & 19 & \\
\hline$>60$ & 3 & 20 & \\
\hline Sex & & & 0.82 \\
\hline Male & 12 & 33 & \\
\hline Female & 1 & 6 & \\
\hline T stage & & & 1.0 \\
\hline pT1-2 & 4 & 11 & \\
\hline pT3-4 & 9 & 28 & \\
\hline $\mathrm{N}$ stage & & & 1.00 \\
\hline $\mathrm{pN}(-)$ & 11 & 31 & \\
\hline $\mathrm{pN}(+)$ & 2 & 8 & \\
\hline Differentiation & & & 0.11 \\
\hline Poor & 3 & 19 & \\
\hline Moderate & 9 & 14 & \\
\hline Well & 1 & 6 & \\
\hline Tumor location & & & 0.01 \\
\hline Upper & 1 & 0 & \\
\hline Middle & 11 & 22 & \\
\hline Lower & 1 & 17 & \\
\hline Type of tumor & & & 1.00 \\
\hline SCC & 13 & 37 & \\
\hline Others & 0 & 2 & \\
\hline Chemotherapy & & & 1.0 \\
\hline $0-2$ cycles & 9 & 25 & \\
\hline$\geq 3$ cycles & 4 & 14 & \\
\hline Lymphadenectomy & & & 0.06 \\
\hline Two-field & 8 & 35 & \\
\hline Three-field & 5 & 4 & \\
\hline Anastomotic site & & & 0.90 \\
\hline Neck & 3 & 7 & \\
\hline Upon aortic arch & 9 & 28 & \\
\hline Below aortic arch & 1 & 4 & \\
\hline
\end{tabular}

SCC, squamous cell carcinoma; PRT, postoperative radiotherapy.

difference for recurrence time of patients with and without PRT, but the MT for patients with PRT was over one month longer than that for patients without PRT. What is more, the patients with PRT were usually advanced TEC [i.e., pT3/4, $\mathrm{pN}(+)$. Therefore, local advanced TEC may benefit from PRT, which had been studied by many researches $(9-11,30)$. We noticed that a few patients recurred in $<3$ months after radical surgery, which may due to micrometastasis that cannot be found using common clinic examinations before surgery and was not cleaned up completely. Prenzel et al (31) found that $15 \%$ of patients with pT1N0M0 carcinoma of the esophagus and even those with submucosal infiltration show nodal micrometastasis. Methods should be used to early discovery the removed or unremoved micrometastasis $(32,33)$.

Lymphatic recurrence was the most common pattern for patients without PRT, $87.9 \%$ in the present study. Other researches also have the same results $(3,22,23)$. Taken in this sense, PRT should be a useful way to reduce recurrence, as sub-clinic lesions or lymphatic micrometastasis can be further controlled. However, the lymphatic system of esophagus presents great complexity. The esophageal wall has a rich network of lymphatic drainage from layer of muscularis mucosa to tunica adventitia. Early EC can be found widely metastasis, even skipping metastasis. At present, two-field lymphadenectomy and three-field lymphadenectomy were the common procedure (in our hospital, two-field lymphadenectomy was the main). Because of the limitation of the operation itself, the upper mediastinum and supraclavicular lymph nodes are difficult to clean up, and they are most likely to become sub-clinical lesions invaded regions. Moreover, when patients are operated via left thoracic incision, we could not clear up the upper paraesophageal nodes and the nodes located in the cervicothoracic junction, due to the occlusion of the aortic arch, left lock artery and subclavian artery. As a result, the lower neck, supraclavicular and the upper mediastinum regions have a high recurrence. In the present study, the recurrence ratios of station 1 and station 2-4 for patients without PRT were 30.0 and $37.2 \%$, totally $67.2 \%$. The lower mediastinum and celiac lymph nodes can be easily cleaned up, so the recurrence ratios of station 5, station 7 , station 8, station 10 and celiac regions were very low (totally $15.7 \%)$. The results were similar to other research $(24,34)$. From what has been discussed above, we may draw that lower neck, supraclavicular regions and upper mediastinum regions (station 1-4) are the hot spots in PRT.

Then we need to think about whether there are differences in postoperative target for different locations of TEC patients. As we know, lymphatic of TEC can drain to different regions, but usually there is one predominant region of drainage. The upper lymphatic of TEC drains upward mainly, the middle lymphatic can drain upward and downward and the lower lymphatic mainly drains downward (35). Because lymph nodes of the middle, lower mediastinum and celiac regions can be easily and thoroughly cleaned up, the CTV should be different from that of patients without esophagectomy. In this study, the lymphatic recurrence ratios in the station 1 and station $2-4$ were totally $80.0,76.3,61.9 \%$, respectively, for upper, middle and lower TEC. The lymphatic recurrence ratios in station 5-10 were totally $0.0,8.1$ and $10.7 \%$, respectively. The lymphatic recurrence ratios in celiac regions were 3.3, 5.0 and $14.3 \%$, respectively. The recurrence rates in station $5-10$ for all TEC and celiac regions for upper and middle TEC were low, so more evidences should be collected to explain whether these regions should be included in CTV of PRT. Many researches $(24,35,36)$ also suggested that PRT target should include supraclavicular and mediastinal regions for all TEC, while celiac lymph node regions should also be included for lower TEC.

In order to further find out the suitable CTV for PRT, we analyzed the pattern of recurrence for patients treated with PRT using the target mentioned above. The lymphatic recurrence ratio decreased (69.2 vs. $87.9 \%$; $\mathrm{P}=0.01)$, while 
the hematological recurrence ratio increased compared to patients without PRT (17.2 vs. 8.0\%; $\mathrm{P}=0.01)$. It indicated that PRT should decrease lymphatic recurrence. For upper TEC, CTV including station 1 and station 2-4 has been an accepted standard. In the present study, only one patient $(2.1 \%)$ was collected and recurred in station 2-4 (infield), indicating that lower recurrence rate after PRT. The negative statistical results of recurrence ratio in station 1 and station 2-4 may due to the limited PRT patients. For middle TEC (68.8\%), the recurrence was mostly in station1 (outfield, 36.4\%) and station 2-4 (infield, 21.2\%). However the recurrence ratio of station 2-4 decreased compared to patients without PRT $(\mathrm{P}=0.03)$, while the recurrence ratio in other regions have no statistic difference for patients with and without PRT. For lower TEC (37.5\%), the recurrence was also mostly in station1 $(38.9 \%)$ and station 2-4 (22.2\%), which were both outfield. The recurrence ratios in station 7 , station 8 and celiac regions (infield) had no statistic difference for patients with and without PRT. Chen et al (37) found that lower TEC had a wide range of celiac lymph nodes metastasis, $34.4 \%$ in nodes along the left gastric artery, $21.7 \%$ in nodes along left cardiac, $17.8 \%$ in nodes along the lesser curvature, $9.4 \%$ in nodes along right cardiac and $6.1 \%$ in nodes along the common hepatic artery at time of surgery. However nodes along the left gastric artery, left cardiac and lesser curvature usually can be cleaned up. Oppedijk et al (38) found that radiotherapy did not decrease the celiac lymph nodes metastasis. For these reasons, we also have no adequate evidence to irradiate the lower mediastinum and celiac regions for middle and lower TEC, which may increase complications or radiotherapy-related death.

For infield recurrences, we might think about whether $50 \mathrm{~Gy}$ of biological effective dose (BED) was enough for sub-clinic or micrometastasis tumor. Moon et al (39) suggested that total radiation dose should be at least 50 Gy in PRT alone. Also, researches $(3,22,38,40)$ showed that the anastomotic recurrence ratio was low ( $4.0 \%$ in my study), we should not include it into CTV. In the past, we usually focused on the tumor bed for PRT of TEC, however, the anatomical structure of the primary esophagus changed after surgery. The recurrence ratio in primary tumor bed was also very low, ranging from 3.6 to $8.8 \%$ (41-43), so primary tumor bed was not indeed for PRT.

In conclusion, for patients treated with standard esophagectomy, the lower neck, supraclavicular regions and upper mediastinal regions (station 1,2 and 4) should be included in the CTV of PRT, while lower mediastinal regions and celiac regions may not be included in CTV. More evidence are needed to find out a suitable BED for PRT. Because this was a retrospective study, potential bias may exist (i.e., more local recurrence patients collected in my department for further treatments). Furthermore, there are many limitations in the present study, such as patients with and without PRT were different [i.e., patients with PRT were usually pT3-4, pN (+)]; Chemotherapy were not very clear in patients without PRT and the used CTV of PRT was still not accepted in some research centers. As a result, we cannot evaluate the efficacy of PRT and chemotherapy. In future, multicentric, perspective, large-scale trials should be conducted to find out a more suitable modality for PRT of EC.

\section{References}

1. Chen W, Zheng R, Baade PD, Zhang S, Zeng H, Bray F, Jemal A, Yu XQ and He J: Cancer statistics in China, 2015. CA Cancer J Clin 66: 115-122, 2016.

2. Chen MF, Chen PT, Lu MS, Lee CP and Chen WC: Survival benefit of surgery to patients with esophageal squamous cell carcinoma. Sci Rep 7: 46139, 2017.

3. Liu Q, Cai XW, Wu B, Zhu ZF, Chen HQ and Fu XL: Patterns of failure after radical surgery among patients with thoracic esophageal squamous cell carcinoma: Implications for the clinical target volume design of postoperative radiotherapy. PLoS One 9: e97225, 2014.

4. Hsu PK, Chen HS, Huang CS, Liu CC, Hsieh CC, Hsu HS, Wu YC and Wu SC: Patterns of recurrence after oesophagectomy and postoperative chemoradiotherapy versus surgery alone for oesophageal squamous cell carcinoma. Br J Surg 104: 90-97, 2017.

5. Markar SR, Noordman BJ, Mackenzie H, Findlay JM, Boshier PR, Ni M, Steyerberg EW, van der Gaast A, Hulshof MCCM, Maynard N, et al: Multimodality treatment for esophageal adenocarcinoma: Multi-center propensity-score matched study. Ann Oncol 28: 519-527, 2017.

6. Kumaran D, John S, Isiah R and Das S: Management of locally advanced carcinoma oesophagus with radiation/chemoradiation: Single institute experience. J Gastrointest Cancer 47: 313-317, 2016.

7. Huang Y, Wang H, Luo G, Zhang Y, Wang L and Li K: A systematic review and network meta-analysis of neoadjuvant therapy combined with surgery for patients with resectable esophageal squamous cell carcinoma. Int J Surg 38: 41-47, 2017.

8. National Comprehensive Cancer Network: Esophageal Cancer Clinical Practice Guidelines in Oncology. http://www.ncen. org/professionals/physician_gls/f_guidelines.asp. Accessed July 1, 2016.

9. Thallinger CM, Kiesewetter B, Raderer M and Hejna M: Preand postoperative treatment modalities for esophageal squamous cell carcinoma. Anticancer Res. 32: 4609-4627, 2012.

10. Zhu Y, Li M, Kong L and Yu J: Postoperative radiation in esophageal squamous cell carcinoma and target volume delineation. Onco Targets Ther 9: 4187-4196, 2016.

11. Ku GY and Ilson DH: Adjuvant (postoperative) therapy for esophageal cancer. Thorac Surg Clin 23: 525-533, 2013.

12. Nishimaki T, Tanaka O, Suzuki T, Aizawa K, Hatakeyama K and Muto T: Patterns of lymphatic spread in thoracic esophageal. Cancer 74: 4-11, 1994

13. Herbella FA, Del Grande JC and Colleoni R; Japanese Society for Disease of the Esophagus: Anatomical analysis of the mediastinal lymph nodes of normal Brazilian subjects according to the classification of the Japanese Society for Diseases of the Esophagus. Surg Today 33: 249-253, 2003.

14. Gotohda N, Nishimura M, Yoshida J, Nagai K and Tanaka N: The pattern of lymphatic metastases in squamous cell carcinoma of the esophagus. Hepatogastroenterology 52: 105-107, 2005.

15. Sgourakis G, Gockel I, Lyros O, Hansen T, Mildenberger P and Lang H: Detection of lymph node metastases in esophageal cancer. Expert Rev Anticancer Ther 11: 601-612, 2011.

16. Ténière P, Hay JM, Fingerhut A and Fagniez PL: Postoperative radiation therapy does not increase survival after curative resection for squamous cell carcinoma of the middle and lower esophagus as shown by a multicenter controlled trial. French University Association for Surgical Research. Surg Gynecol Obstet 173: 123-130, 1991.

17. Rice TW, Adelstein DJ, Chidel MA, Rybicki LA, DeCamp MM, Murthy SC and Blackstone EH: Benefit of postoperative adjuvant chemoradiotherapy in locoregionally advanced esophageal carcinoma. J Thorac Cardiovasc Surg 126: 1590-1596, 2003

18. Yu E, Tai P, Younus J, Malthaner R, Truong P, Stitt L, Rodrigues G, Ash R, Dar R, Yaremko B, et al: Postoperative extended-volume external-beam radiation therapy in high-risk esophageal cancer patients: A prospective experience. Curr Oncol 16: 48-54, 2009.

19. Qiao XY, Wang W, Zhou ZG, Gao XS and Chang JY: Comparison of efficacy of regional and extensive clinical target volumes in postoperative radiotherapy for esophageal squamous cell carcinoma. Int J Radiat Oncol Biol Phys 70: 396-402, 2008. 
20. Zhang W, Liu X, Xiao Z, Wang L, Zhang H, Chen D, Zhou Z, Feng Q, Hui Z, Liang J, et al: Efficacy of intensity-modulated radiotherapy for resected thoracic esophageal squamous cell carcinoma. Thorac Cancer 6: 597-604, 2015.

21. Xu X, Xie HY, Zhou D, Huang RH, Bai YR, Yuan J and Ye M: Comparison and prognostic analysis of adjuvant radiotherapy versus salvage radiotherapy for treatment of radically resected locally advanced esophageal squamous cell carcinoma. Biomed Res Int 2016: 8548694, 2016.

22. Nakagawa S, Kanda T, Kosugi S, Ohashi M, Suzuki T and Hatakeyama K: Recurrence pattern of squamous cell carcinoma of the thoracic esophagus after extended radical esophagectomy with three-field lymphadenectomy. J Am Coll Surg 198: 205-211, 2004.

23. Ninomiya I, Okamoto K, Tsukada T, Kinoshita J, Oyama K, Fushida S, Osugi $\mathrm{H}$ and Ohta T: Recurrence patterns and risk factors following thoracoscopic esophagectomy with radical lymph node dissection for thoracic esophageal squamous cell carcinoma. Mol Clin Oncol 4: 278-284, 2016.

24. Wu SG, Dai MM, He ZY, Sun JY, Lin HX, Lin H and Li Q: Patterns of regional lymph noed recurrence after radical surgery for thoracic esophageal squamous cell carcinoma. Ann Thorac Surg 101: 551-557, 2016.

25. Sugiyama M, Morita M, Yoshida R, Ando K, Egashira A, Takefumi O, Saeki H, Oki E, Kakeji Y, Sakaguchi Y and Maehara Y: Patterns and time of recurrence after complete resection of esophageal cancer. Surg Today 42: 752-758, 2012.

26. Japanese Esophageal Society: Japanese Classification of Esophageal Cancer, 11th Edition: Part I. Esophagus 14: 1-36, 2017.

27. Sobin LH, Gospodarowicz MK and Wittekind C: TNM classification of malignant tumors. 7th edition. Wiley-Blackwell, Oxford, 2010.

28. Rusch VW, Asamura H, Watanabe H, Giroux DJ, Rami-Porta R and Goldstraw P; Members of IASLC Staging Committee: The IASLC lung cancer staging project: A proposal for a new international lymph node map in the forthcoming seventh edition of the TNM classification for lung cancer. J Thorac Oncol 4: 568-577, 2009.

29. Ela Bella AJ, Zhang YR, Fan W, Luo KJ, Rong TH, Lin P, Yang H and $\mathrm{Fu} \mathrm{JH}$ : Maximum standardized uptake value on PET/CT in preoperative assessment of lymph node metastasis from thoracic esophageal squamous cell carcinoma. Chin J Cancer 33: 211-217, 2014.

30. Wong AT, Shao M, Rineer J, Lee A, Schwartz D and Schreiber D: The impact of adjuvant postoperative radiation therapy and chemotherapy on survival after esophagectomy for esophageal carcinoma. Ann Surg 265: 1146-1151, 2017.

31. Prenzel KL, Hölscher AH, Drebber U, Agavonova M, Gutschow CA and Bollschweiler E: Prognostic impact of nodal micrometastasis in early esophageal cancer. Eur J Surg Oncol 38: 314-318, 2012.
32. Mumtaz WR, Hegde V and Yadav N: Micrometastasis detection using special stains in nodal tissues of oral squamous cell carcinoma-a histochemical study. J Clin Diagn Res 10: ZC23-ZC26, 2016.

33. Zhou Z, Qutaish M, Han Z, Schur RM, Liu Y, Wilson DL and Lu ZR: MRI detection of breast cancer micrometastases with a fibronectin-targeting contrast agent. Nat Commun 6: 7984, 2015.

34. Cai WJ and Xin PL: Pattern of relapse in surgical treated patients with thoracic esophageal squamous cell carcinoma and its possible impact on target delineation for postoperative radiotherapy. Radiother Oncol 96: 104-107, 2010.

35. Riquet M, Saab M, Le Pimpec Barthes F and Hidden G: Lymphatic drainage of the esophagus in the adult. Surg Radiol Anat 15: 209-211, 1993

36. Zhang WC, Wang QF, Xiao ZF, Yang LH, Liu XY: Patterns of failure after complete resection of thoracic esophageal squamous cell carcinoma: Implications for postoperative radiation therapy volumes. Chin J Radiat Oncol 21: 38-41, 2012 (In Chinese).

37. Chen J, Liu S, Pan J, Zheng X, Zhu K, Zhu J, Xiao J and Ying M: The pattern and prevalence of lymphatic spread in thoracic oesophageal squamous cell carcinoma. Eur J Cardiothorac Surg 36: 480-486, 2009.

38. Oppedijk V, van der Gaast A, van Lanschot JJ, van Hagen P, van Os R, van Rij CM, van der Sangen MJ, Beukema JC, Rütten $\mathrm{H}$, Spruit $\mathrm{PH}$, et al: Patterns of recurrence after surgery alone versus preoperative chemoradiotherapy and surgery in the CROSS trials. J Clin Oncol 32: 385-391, 2014.

39. Moon S, Kim H, Chie E, Kim J and Park C: Positive impact of radiation dose on disease free survival and locoregional control in postoperative radiotherapy for squamous cell carcinoma of esophagus. Dis Esophagus 22: 298-304, 2009.

40. Li CL, Zhang FL, Wang YD, Han C, Sun GG, Liu Q, Cheng YJ, Jing SW and Yang CR: Characteristics of recurrence after radical esophagectomy with two-field lymph node dissection for thoracic esophageal cancer. Oncol Lett 5: 355-359, 2013.

41. Kim KH, Chang JS, Cha JH, Lee IJ, Kim DJ, Cho BC, Park KR and Lee CG: Optimal adjuvant treatment for curatively resected thoracic esophageal squamous cell carcinoma: A radiotherapy perspective. Cancer Res Treat 49: 168-177, 2017.

42. Yamashita K, Watanabe M, Mine S, Kurogochi T, Okamura A, Hayami M and Imamura Y: Patterns and outcomes of recurrent esophageal cancer after curative esophagectomy. World J Surg 41: 2337-2344, 2017.

43. Wang X, Luo Y, Li M, Yan H, Sun M and Fan T: Recurrence pattern of squamous cell carcinoma in the midthoracic esophagus: Implications for the clinical target volume design of postoperative radiotherapy. Onco Targets Ther 9: 6021-6027, 2016. 